\title{
Fibrinogen/albumin ratio index is an independent predictor of recurrence-free survival in patients with intrahepatic cholangiocarcinoma following surgical resection
}

\author{
Hu Liu ${ }^{1,2+}$, Guoteng Qiu ${ }^{1,2+}$, Fengjuan $\mathrm{Hu}^{3}$ and Hong Wu${ }^{1,2^{*}}$
}

\begin{abstract}
Background: Systemic inflammation and nutritional status are associated with tumor development and progression. This study investigated the prognostic value of fibrinogen/albumin ratio index (FARI) in predicting recurrence-free survival (RFS) in patients with intrahepatic cholangiocarcinoma (ICC) undergoing hepatectomy.

Methods: A retrospective cohort was conducted including patients who received curative hepatectomy for ICC at our hospital between May 2010 and December 2016. We collected the preoperative hematologic parameters and clinical data of all patients. Time-dependent receiver operating characteristic curve was used to identify the optimal cutoff value of FARI. The association between FARI-high and FARI-low group was investigated by using the KaplanMeier method. A nomogram based on the results of univariate and multivariate analysis was established.

Results: A total of 394 patients with ICC who underwent hepatectomy at our hospital were enrolled. K-M analysis revealed that increased FARI was related to reduced RFS $(P<0.001)$. The multivariate analysis indicated that tumor number, tumor-node-metastasis stage, lymph node metastasis, cirrhosis, serum carbohydrate antigen 19-9, and FARI were independent predictors of RFS, and the ROC curve analysis showed that the optimal cutoff value for FARI was 0.084 based on the Youden index. The nomogram for FARI showed satisfactory accuracy in predicting RFS for ICC patients undergoing hepatectomy $(C$ index $=0.663 ; \mathrm{AIC}=3081.07)$.

Conclusion: Preoperative FARI is an independent predictor of RFS in patients undergoing hepatectomy for ICC, and the nomogram can be useful for clinical decision-making in the postoperative management of these patients.
\end{abstract}

Keywords: Intrahepatic cholangiocarcinoma, Fibrinogen, Albumin, Fibrinogen-to-albumin ratio, Prognosis, Surgery

\footnotetext{
* Correspondence: wuhong7801@163.com

${ }^{\dagger} \mathrm{Hu}$ Liu and Guoteng Qiu contributed equally to this work.

'Department of Liver Surgery, Liver Transplantation Division, West China Hospital, Sichuan University, Chengdu 610041, China

${ }^{2}$ Laboratory of Liver Surgery, West China Hospital, Sichuan University, Chengdu 610041, China

Full list of author information is available at the end of the article
}

(c) The Author(s). 2021 Open Access This article is licensed under a Creative Commons Attribution 4.0 International License, which permits use, sharing, adaptation, distribution and reproduction in any medium or format, as long as you give appropriate credit to the original author(s) and the source, provide a link to the Creative Commons licence, and indicate if changes were made. The images or other third party material in this article are included in the article's Creative Commons licence, unless indicated otherwise in a credit line to the material. If material is not included in the article's Creative Commons licence and your intended use is not permitted by statutory regulation or exceeds the permitted use, you will need to obtain permission directly from the copyright holder. To view a copy of this licence, visit http://creativecommons.org/licenses/by/4.0/ The Creative Commons Public Domain Dedication waiver (http://creativecommons.org/publicdomain/zero/1.0/) applies to the data made available in this article, unless otherwise stated in a credit line to the data. 


\section{Introduction}

Hepatocellular carcinoma and intrahepatic cholangiocarcinoma account for $\sim 85 \%$ of primary liver tumors. Intrahepatic cholangiocarcinoma (ICC), which originates in second-order bile ducts, accounts for $10-15 \%$ of hepatobiliary malignancies [1]. The incidence for ICC has been increasing in most areas of the world in recent years $[2,3]$. The 5 -year overall survival for ICC is $\sim 20 \%$; this low rate may be attributable to the aggressivity and heterogeneity of the tumors [4]. Surgery is considered the most effective treatment but only about $20 \%$ of patients undergo potentially curative resection [5]. Chemotherapy is the standard of care for patients with unresectable ICC $[6,7]$, while immunotherapy has recently shown favorable results, suggesting new possibilities in the treatment of ICC [8].

The American Joint Committee on Cancer (AJCC) tumor-node-metastasis (TNM) system is widely used for hepatobiliary cancer staging and can help clinicians to determine the best course of treatment for patients. However, the TNM system has some limitations, specifically with respect to the classification of $\mathrm{T}$ stage. One study showed that the risk of death was lower for TNM stage T3 than for stages T1b and T2 [9], while another reported comparable overall survival rates between stages T2 and T3 [10]. Based on these findings, many researchers have called for a new system for evaluating and predicting the outcome of ICC $[11,12]$.

In order to explore more clinicopathological features that may be related to tumor prognosis, researchers are committed to studying various indicators, such as systemic inflammation, morphology, immunohistochemistry, and surgical methods [13-17]. Systemic inflammation plays a critical role in cancer development and progression. For example, the accumulation of neutrophils within a tumor area was found to be associated with a higher aggressivity of ICC [18], whereas a larger population of CD4+ and CD8+ lymphocytes was linked to better prognosis $[18,19]$. Inflammationrelatedvariables have shown satisfactory predictive value [20-23], such as neutrophil-to-lymphocyte ratio (NLR), $\gamma$-glutamyltransferase-to-lymphocyte ratio (GLR), and albumin-to-alkaline phosphatase (ALP) ratio (AAPR). Poor nutritional status has also been linked to reduced survival rates in cancer [24, 25]. The fibrinogen/albumin ratio index (FARI) was recently established to evaluate long-term survival in cancer patients [26-29] based on the finding that a higher FARI was associated with worse prognosis. However, the value of FARI in predicting the outcome of ICC patients undergoing hepatectomy is unknown. In this study, we evaluated the prognostic value of FARI in these patients and established a nomogram for predicting recurrence-free survival (RFS) based on this index.

\section{Patients and methods}

\section{Study population}

The study enrolled 394 consecutive patients who underwent surgical resection for ICC between May 2010 and December 2016 at the West China Hospital. All patients were newly diagnosed with ICC based on histopathologic examination after surgery and were undergoing surgery for ICC for the first time. Patients' medical records were analyzed, including the hematologic test results obtained closest to the date of surgery. The exclusion criteria were as follows: patients with other primary malignancies or extrahepatic metastasis; patients who had received transarterial chemoembolization, chemotherapy, radiofrequency ablation, or other types of anticancer therapy before surgical resection or who were treated with palliative surgery; and patients with missing clinicopathologic data. Informed consent was obtained from each patient or a relative prior to enrollment. The study was carried out in accordance with the Declaration of Helsinki [30] and the ethical guidelines for clinical studies of the West China Hospital, and the study protocol was reviewed and approved by the ethics committee of West China Hospital (No. 2014-37).

\section{Clinical data collection and follow-up}

Patient records including preoperative hematologic parameters were retrieved from electronic or handwritten medical records at the West China Hospital. The following information was obtained for each patient: age; sex; ascites; cirrhosis; hepatitis B surface antigen (HBsAg); total bilirubin (TBIL); ALP; albumin; carbohydrate antigen 19-9 (CA19-9); tumor size and number; macrovascular and microvascular invasion; TNM stage; tumor differentiation; neutrophil, lymphocyte, and platelet counts; and fibrinogen level in peripheral blood. FARI, NLR, and GLR were calculated as follows: FARI = fibrinogen concentration $(\mathrm{g} / \mathrm{l}) /$ albumin concentration $(\mathrm{g} /$ l); NLR = neutrophil count/lymphocyte count; and GLR $=\gamma$-glutamyltransferase concentration $(\mathrm{U} / \mathrm{l}) /$ lymphocyte count $\left(10^{12} / \mathrm{l}\right)$. AAPR was calculated by dividing serum ALB level (g/l) by serum ALP level (U/l).

The patients were regularly screened for recurrence by monitoring plasma levels of ICC-specific tumor markers and through contrast-enhanced computed tomography performed every 3 months in the first year after surgery, every 6 months in year 2, and annually thereafter [31]. Full blood count and biochemistry, liver function, and other laboratory tests were performed at each visit. Follow-up treatment for patients who experienced recurrence was not recorded. The primary endpoint was RFS, defined as the time from surgery to the date of first recurrence or death. Patients without the above-described events were censored at the last follow-up (in December 2018). 


\section{Statistical analysis}

Statistical analyses were performed using SPSS v26.0 software (SPSS Inc., Chicago, IL, USA) and Prism v8.0 software (GraphPad, La Jolla, CA, USA). Categorical variables were compared using Pearson's chi square test or Fisher's exact test, as appropriate. Continuous data were compared using the Mann-Whitney U test or Student's t test. To calculate the optimal cutoff values of FARI, NLR, GLR, and AAPR for predicting 5-year RFS, we generated receiver operating characteristic (ROC) curves and selected the maximum Youden index as the cutoff [32]. The area under the ROC curve (AUC) provided a measure of overall performance of hematologic markers.
We used the cutoff value of FARI to divide the cohort into 2 groups (FARI-high and -low) and compared their baseline characteristics. Survival curves were generated with the Kaplan-Meier method and were compared with the log-rank test. Variables with a $P$ value $<0.2$ in the univariate Cox proportional hazards regression analysis were included in the multivariate analysis; a nomogram was constructed based on the results [33] using $\mathrm{R} v 4.0 .3$ (https://www.r-project.org/) with 1000 bootstrap resamples. The performance of the nomogram was assessed based on concordance index ( $\mathrm{C}$ index) and Akaike information criterion (AIC); these were also calculated for other variables. A larger $\mathrm{C}$ index indicates a more

Table 1 Relationship between demographic and clinicopathologic characteristics and FARI in patients with intrahepatic cholangiocarcinoma

\begin{tabular}{|c|c|c|c|c|}
\hline Characteristic & Total $(n=394)$ & FARI-high $(n=168)$ & FARI-low $(n=226)$ & $P$ value \\
\hline Age in years, median (IQR) & $59(50-65)$ & $60(52-65)$ & $58(49-65.8)$ & 0.577 \\
\hline Male sex & $191(48.5)$ & $82(48.8)$ & $109(48.2)$ & 0.909 \\
\hline HBsAg positive & $94(23.9)$ & $35(20.8)$ & $59(26.1)$ & 0.206 \\
\hline Ascites & $51(12.9)$ & $25(14.9)$ & $26(11.5)$ & 0.323 \\
\hline TBIL $[\mu \mathrm{mol} / \mathrm{I}]$, mean (SD) & $19.2(39.3)$ & $24.0(57.7)$ & $15.6(14.1)$ & 0.022 \\
\hline ALP [U/I], mean (SD) & $148.7(142.2)$ & $191.0(185.2)$ & $117.3(87.1)$ & $<0.001$ \\
\hline ALB [g/l], mean (SD) & $42.1(4.3)$ & $39.9(4.5)$ & $43.7(3.3)$ & $<0.001$ \\
\hline \multicolumn{5}{|l|}{ CA19-9 } \\
\hline$<22$ & $113(28.7)$ & $38(25.6)$ & 75 (33.2) & \multirow[t]{2}{*}{0.022} \\
\hline$\geq 22$ & $281(71.3)$ & $130(74.4)$ & $151(66.8)$ & \\
\hline \multicolumn{5}{|l|}{ Tumor size } \\
\hline$\leq 5 \mathrm{~cm}$ & $148(37.6)$ & $42(25)$ & 89 (39.4) & \multirow[t]{2}{*}{0.003} \\
\hline$>5 \mathrm{~cm}$ & $246(62.4)$ & $126(75)$ & $137(60.6)$ & \\
\hline Solitary tumor & $291(73.9)$ & $117(69.6)$ & $174(76.9)$ & 0.533 \\
\hline Macrovascular invasion & $60(15.2)$ & $30(17.9)$ & $30(17.9)$ & 0.211 \\
\hline Microvascular invasion & $46(11.7)$ & 19 (11.3) & $27(16.1)$ & 0.846 \\
\hline Cirrhosis & $38(9.6)$ & $17(10.1)$ & $21(12.5)$ & 0.735 \\
\hline \multicolumn{5}{|l|}{ Tumor differentiation } \\
\hline Poor & 287 (72.8) & $129(76.8)$ & $158(69.9)$ & \multirow[t]{2}{*}{0.129} \\
\hline Moderate/well & 107 (27.2) & $39(23.2)$ & $68(30.1)$ & \\
\hline \multicolumn{5}{|l|}{ NLR } \\
\hline High & $268(68.0)$ & $141(62.4)$ & $127(75.6)$ & \multirow[t]{2}{*}{$<0.001$} \\
\hline Low & $126(31.9)$ & 27 (11.9) & 99 (58.9) & \\
\hline \multicolumn{5}{|l|}{ GLR } \\
\hline High & $191(48.5)$ & $100(44.2)$ & $91(54.2)$ & \multirow[t]{2}{*}{$<0.001$} \\
\hline Low & $203(51.5)$ & $68(30.1)$ & $135(80.4)$ & \\
\hline \multicolumn{5}{|l|}{ AAPR } \\
\hline High & $169(42.9)$ & $32(12.2)$ & $137(81.5)$ & \multirow[t]{2}{*}{$<0.001$} \\
\hline Low & $225(57.1)$ & $136(60.2)$ & $89(52.9)$ & \\
\hline
\end{tabular}

Data are presented as $\mathrm{n}(\%)$ unless otherwise indicated

Abbreviations: $A A P R$ albumin-to-alkaline phosphatase ratio, $A L B$ albumin, $A L P$ alkaline phosphatase, $C A 19-9$ carbohydrate antigen 19-9, FARI fibrinogen/albumin ratio index, GLR Y-glutamyltransferase-to-lymphocyte ratio, $H B s A g$ hepatitis B surface antigen, IQR interquartile range, NLR neutrophil-to-lymphocyte ratio, $S D$ standard deviation, TBIL total bilirubin 
accurate prediction [34] while a lower AIC indicates less loss of information and is more representative of the variable [35]. A 2 -sided $\mathrm{P}<0.05$ was considered statistically significant.

\section{Results}

\section{Characteristics of the study population}

The clinicopathologic characteristics of the patients are summarized in Table 1. Of the 394 patients, 191 (48.5\%) were male; the median age was 59 years (interquartile range, $50-65$ years), and $94(23.9 \%)$ were positive for HBsAg. According to the AJCC staging manual (8th edition), tumor size was $\leq 5 \mathrm{~cm}$ in $148(37.6 \%)$ cases and $>5 \mathrm{~cm}$ in $246(62.4 \%)$ cases. The median tumor size in the whole cohort was $5.9 \mathrm{~cm}$. Most cases $(291,73.9 \%)$ had a solitary tumor. A total of 281 patients $(71.3 \%)$ had increased serum CA19-9 (reference value, $22 \mathrm{U} / \mathrm{ml}$ ). Based on the postoperative pathology examination, 102 samples (25.9\%) were lymph node-positive, 60 (15.2\%) showed macrovascular invasion, and 46 (11.7\%) showed microvascular invasion. Cirrhosis and ascites were observed in $38(9.6 \%)$ and 51 (12.9\%) patients, respectively.

We determined the optimal cutoff values of biochemical indices for estimating RFS by plotting ROC curves; the values were 0.084 for FARI, 2.30 for NLR, 41.41 for GLR, and 0.42 for AAPR, with AUCs of $0.606(P=$ 0.001), $0.611(P=0.001), 0.621(P<0.001)$, and $0.621(P$ $<0.001$ ), respectively (Supplementary Fig. 1 ). Based on
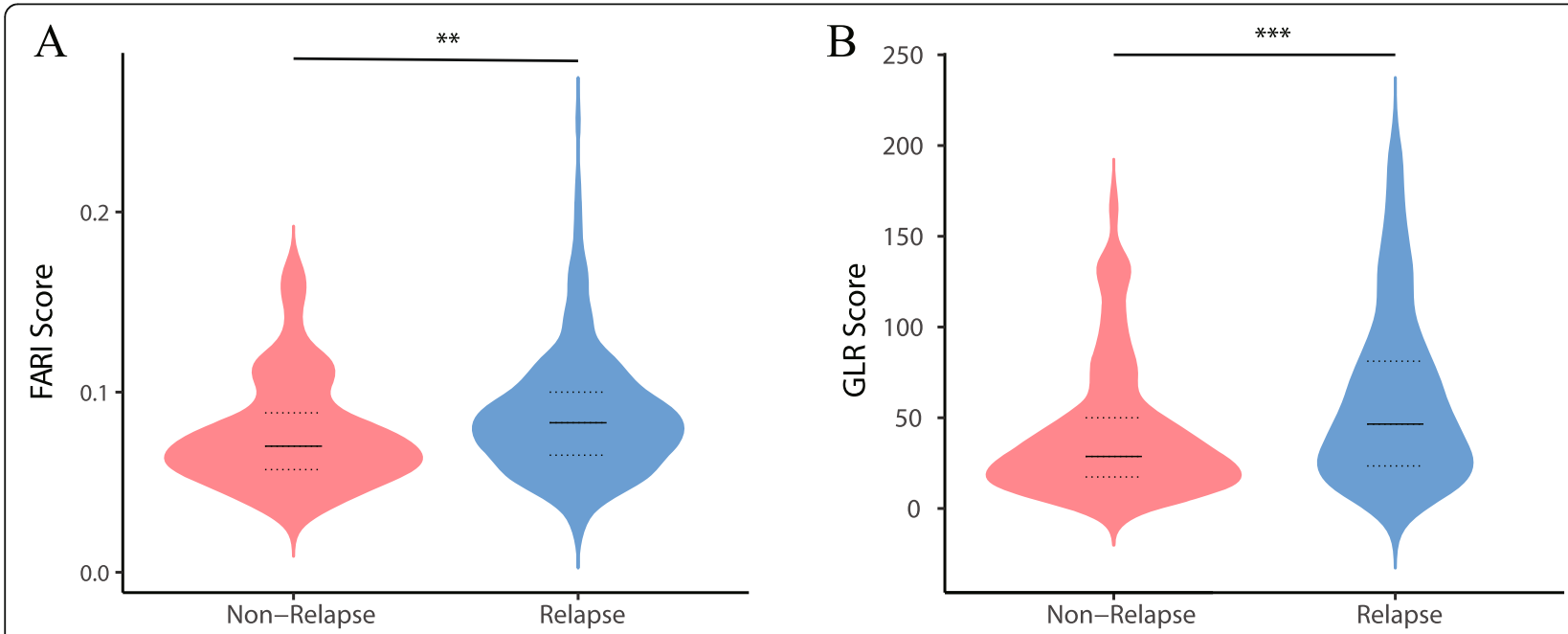

$\mathrm{C}$

$\mathrm{D}$
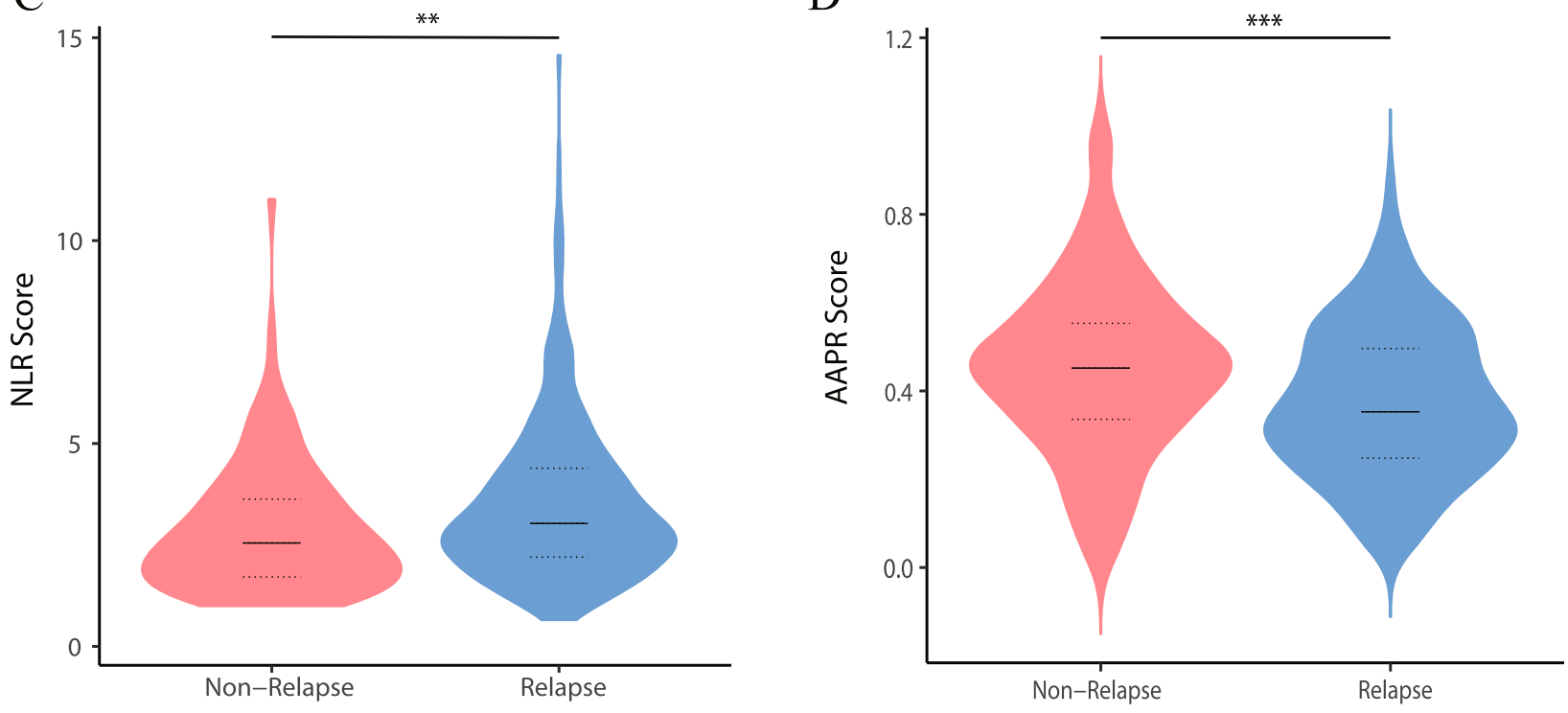

Fig. 1 Scores for different parameters used to predict RFS in patients with ICC. Violin plots showing the distribution of FARI (A), GLR (B), NLR (C), and AAPR score (D) in non-relapsed and relapsed groups at the end of follow-up. Solid lines represent the median value; dotted lines represent quartiles. ${ }^{*} P<0.05$, ${ }^{* *} P<0.01,{ }^{* *} P<0.001$ 
the cutoff value of FARI, we divided the cohort into 2 groups: 168 patients with FARI value $>0.084$ were classified as FARI-high, whereas 268 were stratified into the FARI-low group. Relapsed patients had higher FARI, GLR, and NLR and lower AAPR than non-relapsed patients (Fig. 1). FARI was weakly correlated with NLR ( $\mathrm{r}$ $=0.242, \mathrm{P}<0.001)$ and GLR $(\mathrm{r}=0.235, P<0.001)$ and showed a weakly but statistically significant negative correlation with AAPR $(\mathrm{r}=-0.474, P<0.001)$.

Of the 394 patients, 292 relapsed during the study period. The 1-, 3-, and 5-year overall RFS was 40.6\%, $26.1 \%$, and $23.3 \%$, respectively. The Kaplan-Meier analysis with log-rank test showed that increased FARI, NLR, and GLR and decreased AAPR were associated with worse prognosis (Fig. 2). On the other hand, patients with microvascular invasion, cirrhosis, poor tumor differentiation, tumor size $>5 \mathrm{~cm}$, TNM stage $>$ T2, multiple tumors, or elevated CA19-9 level had lower RFS (Supplementary Fig. 2).

In the univariate Cox regression analysis, 13 clinicopathologic variables were potentially related to RFS $(P<0.2)$ and were analyzed with a multivariate regression model; tumor number, TNM stage, lymph node metastasis, cirrhosis, serum CA19-9, and FARI were identified as independent risk factors for tumor recurrence (Table 2).

\section{Prognostic nomogram for RFS}

A nomogram for predicting RFS was constructed based on the following independent risk factors: tumor

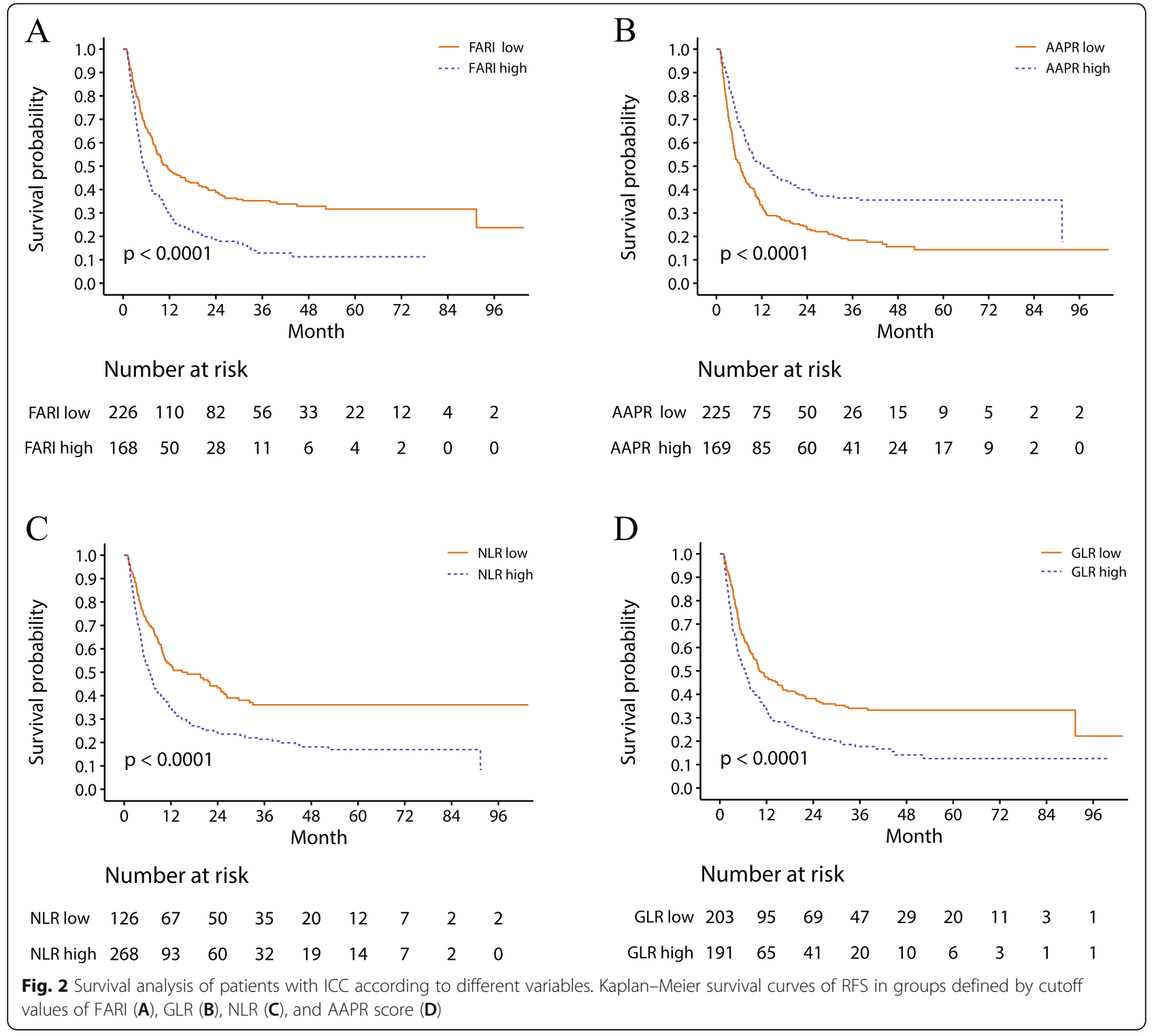


Table 2 Univariate and multivariate analyses of prognostic factors for recurrence-free survival in patients with intrahepatic cholangiocarcinoma

\begin{tabular}{|c|c|c|c|c|c|c|}
\hline \multirow[t]{2}{*}{ Variable } & \multicolumn{3}{|c|}{ Univariate analysis } & \multicolumn{3}{|c|}{ Multivariate analysis } \\
\hline & HR & $95 \% \mathrm{Cl}$ & $P$ value & HR & $95 \% \mathrm{Cl}$ & $P$ value \\
\hline Age $\geq 60$ & 0.983 & $0.781-1.237$ & 0.882 & & & \\
\hline Male sex & 1.157 & $0.919-1.456$ & 0.215 & & & \\
\hline $\mathrm{HBsAg}$ & 1.151 & $0.886-1.495$ & 0.293 & & & \\
\hline Ascites & 1.561 & $1.135-2.146$ & 0.006 & & & \\
\hline Solitary tumor & 1.564 & $1.218-2.009$ & $<0.001$ & 1.308 & $1.006-1.701$ & 0.045 \\
\hline Tumor size $\geq 5 \mathrm{~cm}$ & 1.364 & $1.062-1.751$ & 0.015 & & & \\
\hline Macrovascular invasion & 1.147 & $0.835-1.577$ & 0.397 & & & \\
\hline Microvascular invasion & 1.774 & $1.273-2.473$ & 0.001 & & & \\
\hline Lymph node metastasis & 2.516 & $1.958-3.234$ & $<0.001$ & 1.918 & $1.444-2.548$ & $<0.001$ \\
\hline Cirrhosis & 1.707 & $1.202-2.424$ & 0.003 & 1.715 & $1.190-2.472$ & 0.004 \\
\hline CA19-9 $\geq 22$ & 1.770 & $1.350-2.322$ & $<0.001$ & 1.606 & $1.214-2.123$ & 0.001 \\
\hline Liver capsule invasion & 1.310 & $1.016-1.688$ & 0.037 & & & \\
\hline TNM > T2 & 1.724 & $1.292-2.300$ & $<0.001$ & 1.732 & $1.042-2.879$ & 0.034 \\
\hline FARI & & & $<0.001$ & & & 0.016 \\
\hline Low & Ref & & & & & \\
\hline High & 1.790 & $1.419-2.257$ & & 1.355 & $1.058-1.737$ & \\
\hline NLR & & & $<0.001$ & & & \\
\hline Low & Ref & & & & & \\
\hline High & 1.714 & $1.322-2.221$ & & & & \\
\hline GLR & & & $<0.001$ & & & \\
\hline Low & Ref & & & & & \\
\hline High & 1.627 & $1.291-2.050$ & & & & \\
\hline AAPR & & & $<0.001$ & & & \\
\hline High & Ref & & & & & \\
\hline Low & 1.695 & $1.335-2.152$ & & & & \\
\hline
\end{tabular}

$P$ values in boldface are statistically significant $(P<0.05)$

Abbreviations: AAPR albumin-to-alkaline phosphatase ratio, CA19-9 carbohydrate antigen 19-9, FARI fibrinogen/albumin ratio index, GLR Y-glutamyltransferase-tolymphocyte ratio, $H B S A g$ hepatitis B surface antigen, $H R$ hazard ratio, NLR neutrophil-to-lymphocyte ratio, Ref reference, TNM tumor-node-metastasis stage

number (solitary vs multiple), TNM stage ( $\leq \mathrm{T} 2$ vs $>$ T2), lymph node metastasis (yes vs no), cirrhosis (yes vs no), serum CA19-9 ( $\leq 22$ or $>22$ ), and FARI (high vs low) (Fig. 3). Each factor was associated with a score, the sum of which predicted the 1- and 3-year recurrence probability of patients. The calibration plot showed satisfactory consistency between the nomogram-predicted RFS and actual survival outcomes (Supplementary Fig. 3). Furthermore, the discriminatory capacity of the nomogram and other parameters was evaluated by comparing $C$ index and AIC values (Table 3). The $C$ index of the nomogram was 0.663 ( $95 \%$ confidence interval, 0.630-0.696), which was higher than the $C$ indices of NLR (0.654), GLR (0.652), and AAPR (0.655). These results indicate that FARI better predicts RFS than these other variables.

\section{Discussion}

ICC has poor prognosis because of the aggressivity and heterogeneity of the tumors. As the current AJCC TNM staging system is inadequate for prognostic evaluation of ICC patients who undergo hepatectomy, better tools that can guide clinical decision-making are needed.

Noninvasive markers such as the standard inflammatory indicators NLR, GLR, and AAPR have been used to monitor the progression and predict the outcome of malignant tumors [20-22]. These can easily be calculated by obtaining neutrophil and lymphocyte counts or by measuring $\gamma$-glutamyltransferase, serum albumin, and ALP levels. Neutrophil transmigration across the epithelium causes the disruption of epithelial adherens junctions through the release of elastase [36], which can promote tumor progression. Lymphocytes are associated 


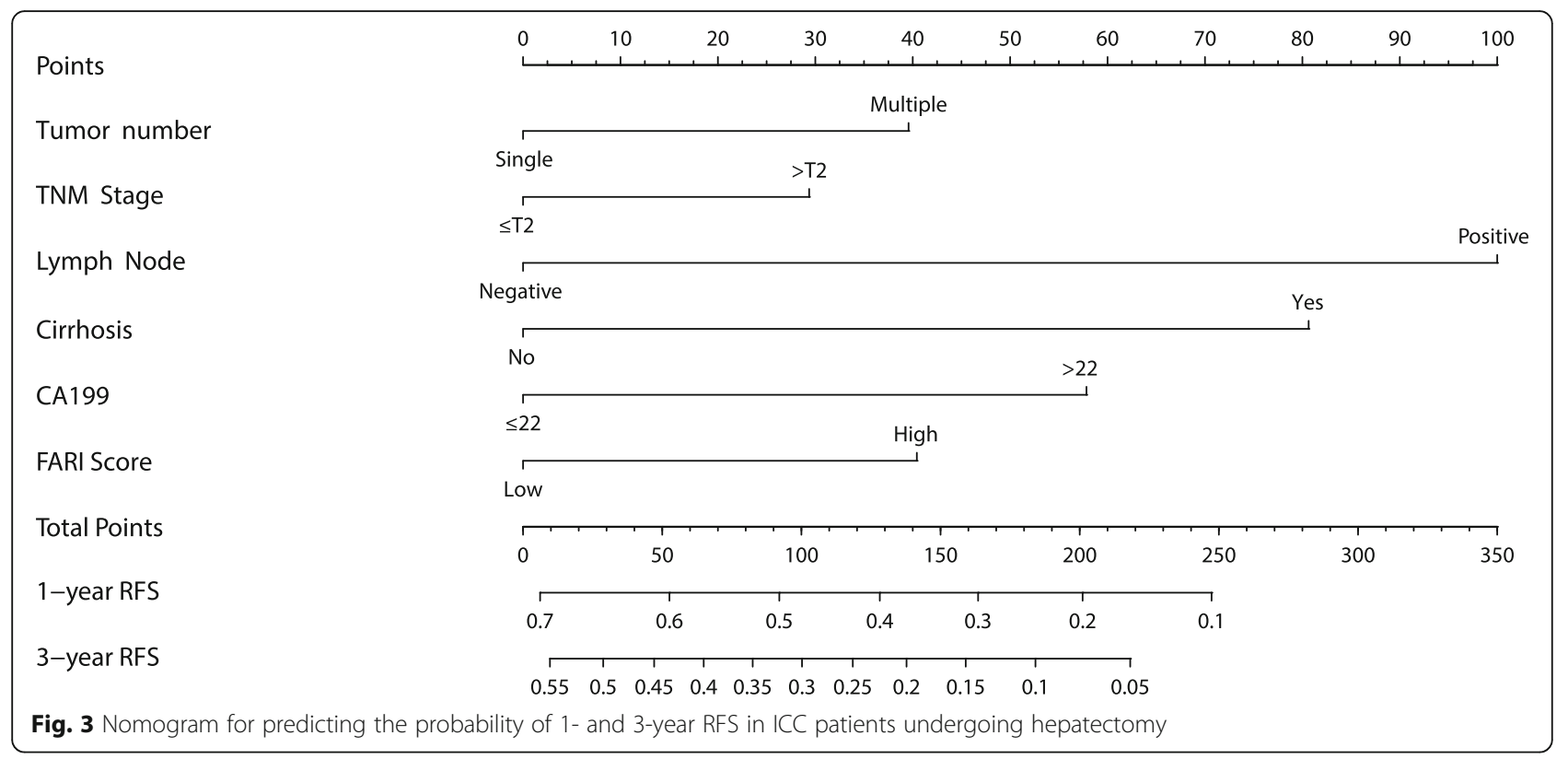

with self-immunity, and patients with malignant tumors are often in a state of immunosuppression that promotes tumor growth, invasion, and metastasis [37, 38]. Immunologic markers are influenced by infection and bone marrow suppression induced by chemotherapy, radiotherapy, or other factors, which reduces their predictive value. As a biochemical marker, FARI is more stable in the circulation and has been used to evaluate long-term prognosis in various cancers including pancreatic ductal adenocarcinoma [39], gastrointestinal stromal tumors [26], and colorectal liver metastases [27]. In this study, we evaluated the prognostic value of FARI for ICC. The optimal cutoff value for FARI in the ROC curve analysis was 0.084 , which diverges from the value of 0.076 reported for colorectal liver metastases [26] and the value of 0.08 in gallbladder cancer [28]. The reason for this discrepancy in the cutoff value among tumor types is unclear, but it may be attributable to differences in the biological characteristics of each tumor.

Table 3 Predictive value of the FARI-based nomogram and 3 variables for recurrence-free survival in patients with intrahepatic cholangiocarcinoma

\begin{tabular}{lllll}
\hline Parameter & C index & $\mathbf{9 5 \% ~ C l}$ & $\boldsymbol{P}$ value & AIC \\
\hline FARI & 0.663 & $0.630-0.696$ & $<0.001$ & 3081.07 \\
NLR & 0.654 & $0.622-0.686$ & $<0.001$ & 3079.11 \\
GLR & 0.652 & $0.619-0.685$ & $<0.001$ & 3079.93 \\
AAPR & 0.655 & $0.622-0.688$ & $<0.001$ & 3082.09
\end{tabular}

Abbreviations: $A A P R$ albumin-to-alkaline phosphatase ratio, AIC Akaike information criterion, $\mathrm{Cl}$ confidence interval, $F A R I$ fibrinogen/albumin ratio index, GLR Y-glutamyltransferase-to-lymphocyte ratio, NLR neutrophil-to-lymphocyte ratio
We divided the cohort into FARI-high and -low groups according to the cutoff value of FARI. Patients in the former group had a larger tumor size, elevated serum CA19-9, lymph node metastasis, and elevated TBIL and ALP levels, suggesting that FARI can reflect disease progression and metastasis in ICC. We also found that a high FARI was correlated with inflammatory indicators including high NLR and GLR and low AAPR. Moreover, the survival analysis revealed that RFS was shorter in ICC patients with a high FARI than in those with a low FARI. A nomogram was constructed based on 6 independent prognostic factors that significantly influenced RFS in the univariate and multivariate analyses, including tumor number, TNM stage, lymph node metastasis, cirrhosis, serum CA19-9, and FARI score. In our assessment of nomogram performance in predicting RFS, the $\mathrm{C}$ index and AIC were 0.663 and 3081.07, respectively, which were higher than the values for inflammatory indicators. Thus, FARI may be useful for predicting the clinical outcome of patients with ICC undergoing hepatectomy.

Fibrinogen is a large fibrous glycoprotein produced by hepatocytes that has been implicated in cancer growth and metastasis [39]. It is frequently detected in tumors and contributes to the formation of tumor-reactive stroma; moreover, fibrogen can promote tumor angiogenesis by binding several growth factors including fibroblast growth factor 2 (FGF-2) and vascular endothelial growth factor (VEGF), leading to tumor progression $[40,41]$. Fibrinogen was shown to promote the malignant transformation of tumors by inducing epithelial-tomesenchymal transition via the mammalian target of rapamycin $(\mathrm{mTOR}) /$ protein kinase $\mathrm{B}(\mathrm{AKT})$ signaling 
pathway [42], and inhibited the cytotoxic activities of natural killer cells in tumors [43]. It has been found to be a key marker in progression of colon cancer [44]. Thus, fibrinogen is a useful marker for monitoring cancer progression.

Albumin is the most abundant protein in human serum and reflects the biosynthetic function of the liver and as well as the preoperative nutritional status of patients. Malnutrition is frequently observed and is related to outcome in various malignancies. Cancer-related malnutrition is associated with impaired immune function and increased proinflammatory cytokine levels, and some studies have shown that lower preoperative albumin level was associated with poor prognosis [45-47]. All of these factors contribute to low survival in cancer patients [48]. Thus, albumin level is also a useful marker for evaluating clinical outcomes in cancer [49].

There were some limitations to our study. First, the single-center retrospective design may have introduced a bias in our analyses. Second, our sample size was small and there was no external validation of our results. Third, the $\mathrm{C}$ index of the nomogram was not ideal, as a high predictive value is not equivalent to clinical applicability; thus, our nomogram needs to be improved by including other clinical variables. In addition, compared with existing biomarkers, the AUC of FARI is relatively low, so the application value of FARI might be limited. Although excellent performance had been found in tumors [26-29], well-designed researches are still needed to explore the applicability in I CC. Finally, we did not investigate the mechanisms by which fibrinogen and albumin influence ICC recurrence. Further studies using animal models are needed in order to address this point.

\section{Conclusion}

The results of this study demonstrate that preoperative FARI is an independent prognostic factor for RFS in patient with ICC undergoing hepatectomy. A high FARI was associated with elevated risk of postoperative recurrence, and a nomogram that included FARI was a better predictor of recurrence than NLR, GLR, and AAPR. Thus, FARI is an objective, low-cost, easily measurable, and noninvasive prognostic indicator that can aid clinical decision-making in the management of ICC following hepatectomy.

\section{Supplementary Information}

The online version contains supplementary material available at https://doi. org/10.1186/s12957-021-02330-2.

Additional file 1: Supplementary Figure 1. Prognostic value of FARI, GLR, NLR, and AAPR for RFS in ICC patients evaluated by ROC curve analysis. (EPS $569 \mathrm{~kb}$ )
Additional file 2: Supplementary Figure 2. Survival analysis of patients with ICC according to clinicopathologic variables. (A-G) KaplanMeier survival curves of RFS in groups defined by cirrhosis (A), MVI (B), differentiation (C), TNM stage (D), tumor size (E), CA-199 (F), and tumor number (G). (EPS 3398 kb)

Additional file 3: Supplementary Figure 3. Calibration plot of nomogram-predicted3-year RFS in patients with ICC. (EPS 620 kb)

\section{Acknowledgements}

Not applicable.

\section{Authors' contributions}

$\mathrm{HL}$ and $\mathrm{HW}$ : conceptualization. $\mathrm{HL}, \mathrm{GQ}$, and $\mathrm{FH}$ : data curation. $\mathrm{HL}$ and $\mathrm{GQ}$ : data analysis. HW: supervision. HL and GQ: manuscript writing (original draft). The authors read and approved the final manuscript.

\section{Funding}

This work was supported by grants from the National Key Technologies R\&D Program (2018YFC1106800), the Natural Science Foundation of China (82002572, 82002967, 81972747 and 81872004), the fellowship of China National Postdoctoral Program for Innative Talents (BX20200225,

BX20200227), and the 1.3.5 project for disciplines of excellence, West China Hospital, Sichuan University (ZYJC18008)

\section{Availability of data and materials}

The analyzed data sets generated during the study are available from the corresponding author on reasonable request.

\section{Declarations}

Ethics approval and consent to participate

The study was conducted in accordance with the Ethics Committee of the West China Hospital and the 1964 Helsinki Declaration. Informed consent was obtained from all participants included in the study.

Consent for publication

Not applicable.

\section{Competing interests}

The authors declare that they have no competing interests.

\section{Author details}

'Department of Liver Surgery, Liver Transplantation Division, West China Hospital, Sichuan University, Chengdu 610041, China. ${ }^{2}$ Laboratory of Liver Surgery, West China Hospital, Sichuan University, Chengdu 610041, China

${ }^{3}$ The Center of Gerontology and Geriatrics, West China Hospital, Sichuan University, Chengdu 610041, China.

Received: 31 March 2021 Accepted: 8 July 2021

Published online: 20 July 2021

References

1. Bray F, Ferlay J, Soerjomataram I, Siegel RL, Torre LA, Jemal A. Global cancer statistics 2018: GLOBOCAN estimates of incidence and mortality worldwide for 36 cancers in 185 countries. CA Cancer J Clin. 2018(68):394-424. https:// doi.org/10.3322/caac.21492.

2. Khan SA, Tavolari S, Brandi G. Cholangiocarcinoma: epidemiology and risk factors. Liver Int. 2019:39(Suppl 1):19-31. https://doi.org/10.1111/liv.14095.

3. Rizvi S, Khan SA, Hallemeier CL, Kelley RK, Gores GJ. Cholangiocarcinoma evolving concepts and therapeutic strategies. Nat Rev Clin Oncol. 2018; 15(2):95-111. https://doi.org/10.1038/nrclinonc.2017.157.

4. Brown KM, Parmar AD, Geller DA. Intrahepatic cholangiocarcinoma. Surg Oncol Clin N Am. 2014;23(2):231-46. https://doi.org/10.1016/j. soc.2013.10.004.

5. Bridgewater J, Galle PR, Khan SA, Llovet JM, Park JW, Patel T, et al Guidelines for the diagnosis and management of intrahepatic cholangiocarcinoma. J Hepatol. 2014;60(6):1268-89. https://doi.org/10.1016/j. jhep.2014.01.021.

6. Bridgewater J, Lopes A, Palmer D, Cunningham D, Anthoney A, Maraveyas A, et al. Quality of life, long-term survivors and long-term outcome from the 
ABC-02 study. Br J Cancer. 2016;114(9):965-71. https://doi.org/10.1038/bjc.2 016.64 .

7. Valle J, Wasan H, Palmer DH, Cunningham D, Anthoney A, Maraveyas A, et al. Cisplatin plus gemcitabine versus gemcitabine for biliary tract cancer. N Engl J Med. 2010;362(14):1273-81. https://doi.org/10.1056/NEJMoa 0908721.

8. Klein O, Kee D, Nagrial A, Markman B, Underhill C, Michael M, et al. Evaluation of combination nivolumab and ipilimumab immunotherapy in patients with advanced biliary tract cancers: subgroup analysis of a phase 2 nonrandomized clinical trial. JAMA Oncol. 2020;6(9):1405-9. https://doi.org/1 0.1001/jamaoncol.2020.2814.

9. Spolverato G, Bagante F, Weiss M, Alexandrescu S, Marques HP, Aldrighetti $L$, et al. Comparative performances of the 7th and the 8th editions of the American Joint Committee on Cancer staging systems for intrahepatic cholangiocarcinoma. J Surg Oncol. 2017;115(6):696-703. https://doi.org/10.1 $002 /$ jso.24569

10. Kang SH, Hwang S, Lee YJ, Kim KH, Ahn CS, Moon DB, et al. Prognostic comparison of the 7th and 8th editions of the American Joint Committee on Cancer staging system for intrahepatic cholangiocarcinoma. J Hepatobiliary Pancreat Sci. 2018;25(4):240-8. https://doi.org/10.1002/jhbp.543.

11. Yamamoto $Y$, Sugiura $T$, Okamura $Y$, Ito $T$, Ashida R, Ohgi $K$, et al. The evaluation of the eighth edition of the AJCC/UICC staging system for intrahepatic cholangiocarcinoma: a proposal of a modified new staging system. J Gastrointest Surg. 2020;24(4):786-95. https://doi.org/10.1007/s11 605-019-04185-1.

12. Cheng Z, Lei Z, Si A, Yang P, Luo T, Guo G, et al. Modifications of the AJCC 8th edition staging system for intrahepatic cholangiocarcinoma and proposal for a new staging system by incorporating serum tumor markers. HPB (Oxford). 2019;21 (12):1656-66. https://doi.org/10.1016/j.hpb.2019.05.010.

13. Tian L, Ma J, Ma L, Zheng B, Liu L, Song D, et al. PD-1/PD-L1 expression profiles within intrahepatic cholangiocarcinoma predict clinical outcome. World J Surg Oncol. 2020;18(1):303. https://doi.org/10.1186/s12957-020-02 $082-5$

14. Wu W, Cheng Q, Chen J, Chen D, Feng X, Wu J. Left-side vs. right-side hepatectomy for hilar cholangiocarcinoma: a meta-analysis. World J Surg Oncol. 2021:19(1):107. https://doi.org/10.1186/s12957-021-02213-6.

15. Yamashita S, Morine Y, Imura S, Ikemoto T, Saito Y, Takasu C, et al. A new pathological classification of intrahepatic cholangiocarcinoma according to protein expression of SSTR2 and Bcl2. World J Surg Oncol. 2021;19(1):142. https://doi.org/10.1186/s12957-021-02216-3.

16. Ishii T, Ito T, Sumiyoshi S, Ogiso S, Fukumitsu K, Seo S, et al. Clinicopathological features and recurrence patterns of combined hepatocellular-cholangiocarcinoma. World J Surg Oncol. 2020;18(1):319. https://doi.org/10.1186/s12957-020-02099-w.

17. Zhang Y, Chen S, Li J, Dai W, Qian Y. Immune infiltrating cells in cholangiocarcinoma may become clinical diagnostic markers: based on bioinformatics analysis. World J Surg Oncol. 2021;19(1):59. https://doi.org/1 0.1186/s12957-021-02168-8

18. Mao ZY, Zhu GQ, Xiong M, Ren L, Bai L. Prognostic value of neutrophil distribution in cholangiocarcinoma. World I Gastroenterol. 2015;21(16): 4961-8. https://doi.org/10.3748/wjg.v21.i16.4961.

19. Miura T, Yoshizawa T, Hirai H, Seino H, Morohashi S, Wu Y, et al. Prognostic impact of CD163+ macrophages in tumor stroma and CD8+ T-cells in cancer cell nests in invasive extrahepatic bile duct cancer. Anticancer Res. 2017;37:183-90. https://doi.org/10.21873/anticanres.11304.

20. Kim CY, Kim SY, Song JH, Kim YS, Jeong SJ, Lee JG, et al. Usefulness of the preoperative prognostic nutritional index score as a predictor of the outcomes of lung transplantation: a single-institution experience. Clin Nutr. 2019;38(5):2423-9. https://doi.org/10.1016/j.clnu.2018.10.027.

21. Wang JJ, Li H, Li JX, Xu L, Wu H, Zeng Y. Preoperative gammaglutamyltransferase to lymphocyte ratio predicts long-term outcomes in intrahepatic cholangiocarcinoma patients following hepatic resection. World J Gastroenterol. 2020;26(13):1501-12. https://doi.org/10.3748/wjg.v26.113.1501.

22. Cai X, Chen Z, Chen J, Ma X, Bai M, Wang T, et al. Albumin-to-alkaline phosphatase ratio as an independent prognostic factor for overall survival of advanced hepatocellular carcinoma patients without receiving standard anticancer therapies. J Cancer. 2018;9(1):189-97. https://doi.org/10.7150/jca.21799.

23. Zhang Z, Zhou Y, Hu K, Huang Y. Investigating effects of preoperative inflammatory biomarkers on predicting survival outcomes of intrahepatic cholangiocarcinoma after curative resection. World J Surg Oncol. 2020;18(1): 272. https://doi.org/10.1186/s12957-020-02053-w.
24. Marshall KM, Loeliger J, Nolte L, Kelaart A, Kiss NK. Prevalence of malnutrition and impact on clinical outcomes in cancer services: a comparison of two time points. Clin Nutr. 2019;38(2):644-51. https://doi. org/10.1016/j.clnu.2018.04.007.

25. Arends J, Bachmann P, Baracos V, Barthelemy N, Bertz H, Bozzetti F, et al. ESPEN guidelines on nutrition in cancer patients. Clin Nutr. 2017;36(1):11-48. https://doi.org/10.1016/j.clnu.2016.07.015.

26. Cao X, Cui J, Yu T, Li Z, Zhao G. Fibrinogen/albumin ratio index is an independent prognosis predictor of recurrence-free survival in patients after surgical resection of gastrointestinal stromal tumors. Front Oncol. 2020;10: 1459. https://doi.org/10.3389/fonc.2020.01459.

27. Wang $Y Y$, Liu ZZ, Xu D, Liu M, Wang K, Xing BC. Fibrinogen-albumin ratio index (FARI): a more promising inflammation-based prognostic marker for patients undergoing hepatectomy for colorectal liver metastases. Ann Surg Oncol. 2019;26(1 1):3682-92. https://doi.org/10.1245/s10434-019-07586-3.

28. Xu Q, Yan Y, Gu S, Mao K, Zhang J, Huang P, et al. A novel inflammationbased prognostic score: the fibrinogen/albumin ratio predicts prognoses of patients after curative resection for hepatocellular carcinoma. J Immunol Res. 2018:2018:4925498-11. https://doi.org/10.1155/2018/4925498.

29. Sun DW, An L, Lv GY. Albumin-fibrinogen ratio and fibrinogen-prealbumin ratio as promising prognostic markers for cancers: an updated meta-analysis. World J Surg Oncol. 2020;18(1):9. https://doi.org/10.1 186/s12957-020-1786-2.

30. Carlson RV, Boyd KM, Webb DJ. The revision of the Declaration of Helsinki: past, present and future. Br J Clin Pharmacol. 2004;57(6):695-713. https://doi. org/10.1111/j.1365-2125.2004.02103.x.

31. Primrose JN, Fox RP, Palmer DH, Malik HZ, Prasad R, Mirza D, et al. Capecitabine compared with observation in resected biliary tract cancer (BILCAP): a randomised, controlled, multicentre, phase 3 study. Lancet Oncol. 2019;20(5):663-73. https://doi.org/10.1016/s1470-2045(18)30915-x.

32. Akobeng AK. Understanding diagnostic tests 3: receiver operating characteristic curves. Acta Paediatr. 2007;96(5):644-7. https://doi.org/1 0.1111/j.1651-2227.2006.00178.x.

33. Harrell FE Jr, Lee KL, Mark DB. Multivariable prognostic models: issues in developing models, evaluating assumptions and adequacy, and measuring and reducing errors. Stat Med. 1996;15(4):361-87. https://doi.org/10.1002/ (sici)1097-0258(19960229)15:4<361::Aid-sim168>3.0.Co;2-4.

34. Wang Y, Li J, Xia Y, Gong R, Wang K, Yan Z, et al. Prognostic nomogram for intrahepatic cholangiocarcinoma after partial hepatectomy. J Clin Oncol. 2013;31(9):1188-95. https://doi.org/10.1200/jco.2012.41.5984.

35. Li H, Li J, Wang J, Liu H, Cai B, Wang G, et al. Assessment of liver function for evaluation of long-term outcomes of intrahepatic cholangiocarcinoma: a multi-institutional analysis of 620 patients. Front Oncol. 2020;10:525. https:// doi.org/10.3389/fonc.2020.00525.

36. Ginzberg HH, Cherapanov V, Dong Q, Cantin A, McCulloch CA, Shannon PT, et al. Neutrophil-mediated epithelial injury during transmigration: role of elastase. Am J Physiol Gastrointest Liver Physiol. 2001;281(3):G705-17. https://doi.org/10.1152/ajpgi.2001.281.3.G705.

37. Wu SD, Ma YS, Fang Y, Liu LL, Fu D, Shen XZ. Role of the microenvironment in hepatocellular carcinoma development and progression. Cancer Treat Rev. 2012;38(3):218-25. https://doi.org/10.1016/j.ctrv.2011.06.010.

38. Lee WC, Wu TJ, Chou HS, Yu MC, Hsu PY, Hsu HY, et al. The impact of CD4+ CD25+ T cells in the tumor microenvironment of hepatocellular carcinoma. Surgery. 2012:151(2):213-22. https://doi.org/10.1016/j.surg.2011.07.029.

39. Zhang D, Zhou X, Bao W, Chen Y, Cheng L, Qiu G, et al. Plasma fibrinogen levels are correlated with postoperative distant metastasis and prognosis in esophageal squamous cell carcinoma. Oncotarget. 2015;6:38410-20. https:/ doi.org/10.18632/oncotarget.4800.

40. Sahni A, Simpson-Haidaris PJ, Sahni SK, Vaday GG, Francis CW. Fibrinogen synthesized by cancer cells augments the proliferative effect of fibroblast growth factor-2 (FGF-2). J Thromb Haemost. 2008;6(1):176-83. https://doi. org/10.1111/j.1538-7836.2007.02808.x

41. Simpson-Haidaris PJ, Rybarczyk B. Tumors and fibrinogen. The role of fibrinogen as an extracellular matrix protein. Ann N Y Acad Sci. 2001;936: 406-25.

42. Zhang F, Wang Y, Sun P, Wang ZQ, Wang DS, Zhang DS, et al. Fibrinogen promotes malignant biological tumor behavior involving epithelialmesenchymal transition via the $\mathrm{p}-\mathrm{AKT} / \mathrm{p}-\mathrm{mTOR}$ pathway in esophageal squamous cell carcinoma. J Cancer Res Clin Oncol. 2017;143(12):2413-24. https://doi.org/10.1007/s00432-017-2493-4.

43. Palumbo JS, Talmage KE, Massari JV, La Jeunesse CM, Flick MJ, Kombrinck $\mathrm{KW}$, et al. Platelets and fibrin(ogen) increase metastatic potential by 
impeding natural killer cell-mediated elimination of tumor cells. Blood. 2005; 105(1):178-85. https://doi.org/10.1182/blood-2004-06-2272.

44. Papila Kundaktepe B, Papila C. The clinical significance of preoperative plasma fibrinogen levels and platelet counts in resectable colon cancer. World I Surg Oncol. 2021;19(1):69. https://doi.org/10.1186/s12957-021-02180-y.

45. Chi J, Xie Q, Jia J, Liu X, Sun J, Chen J, et al. Prognostic value of albumin/ globulin ratio in survival and lymph node metastasis in patients with cancer: a systematic review and meta-analysis. J Cancer. 2018;9(13):2341-8. https://doi.org/10.7150/jca.24889.

46. Lv GY, An L, Sun XD, Hu YL, Sun DW. Pretreatment albumin to globulin ratio can serve as a prognostic marker in human cancers: a meta-analysis. Clin Chim Acta. 2018;476:81-91. https://doi.org/10.1016/j.cca.2017.11.019.

47. Deng Y, Pang Q, Miao RC, Chen W, Zhou YY, Bi JB, et al. Prognostic significance of pretreatment albumin/globulin ratio in patients with hepatocellular carcinoma. Onco Targets Ther. 2016;9:5317-28. https://doi. org/10.2147/ott.S109736.

48. Argilés JM. Cancer-associated malnutrition. Eur J Oncol Nurs. 2005;9(Suppl 2):S39-50. https://doi.org/10.1016/j.ejon.2005.09.006.

49. Moujaess E, Fakhoury M, Assi T, Elias H, El Karak F, Ghosn M, et al. The therapeutic use of human albumin in cancer patients' management. Crit Rev Oncol Hematol. 2017;120:203-9. https://doi.org/10.1016/j.critrevonc.201 7.11.008.

\section{Publisher's Note}

Springer Nature remains neutral with regard to jurisdictional claims in published maps and institutional affiliations.

Ready to submit your research? Choose BMC and benefit from:

- fast, convenient online submission

- thorough peer review by experienced researchers in your field

- rapid publication on acceptance

- support for research data, including large and complex data types

- gold Open Access which fosters wider collaboration and increased citations

- maximum visibility for your research: over $100 \mathrm{M}$ website views per year

At $\mathrm{BMC}$, research is always in progress.

Learn more biomedcentral.com/submissions 